HEALTHCARE DELIVERY

\title{
Appropriate indications for positron emission tomography/computed tomography: College of Nuclear Physicians of the Colleges of Medicine of South Africa
}

\begin{abstract}
M Sathekge, J M Warwick, A Doruyter, M Vorster
Prof. Mike Sathekge is a nuclear physician in the Department of Nuclear Medicine at Steve Biko Academic Hospital and the Faculty of Health Sciences, University of Pretoria, South Africa, and president of the College of Nuclear Physicians of South Africa (CNP). He has an interest in positron emission tomography/computed tomography (PET/CT) and targeted radionuclide therapy. Prof. James Warwick is a nuclear physician in the Division of Nuclear Medicine at Tygerberg Academic Hospital and the Faculty of Medicine and Health Sciences, Stellenbosch University, Tygerberg, Cape Town, South Africa, and secretary of the CNP. He is responsible for clinical operations at the Western Cape Academic PET/CT Centre. Dr Alex Doruyter is a nuclear physician and Medical Research Council clinical PhD scholar in the Division of Nuclear Medicine at Tygerberg Academic Hospital and Stellenbosch University, and Prof. Mariza Vorster is a nuclear medicine physician at the Department of Nuclear Medicine, University of Pretoria. She has a special interest in PET/CT and is a council member of the CNP.
\end{abstract}

Corresponding author: M Sathekge (mike.sathekge@up.ac.za)

\begin{abstract}
Individualised patient treatment approaches demand precise determination of initial disease extent combined with early, accurate assessment of response to treatment, which is made possible by positron emission tomography/computed tomography (PET/CT). PET is a non-invasive tool that provides tomographic images and quantitative parameters of perfusion, cell viability, proliferation and/or metabolic activity of tissues. Fusion of the functional information with the morphological detail provided by CT as PET/CT can provide clinicians with a sensitive and accurate one-step whole-body diagnostic and prognostic tool, which directs and changes patient management. Three large-scale national studies published by the National Oncologic PET Registry in the USA have shown that imaging with PET changes the intended patient management strategy in $36.5 \%$ to $49 \%$ of cases, with consistent results across all cancer types. The proven clinical effectiveness and growing importance of PET/CT have prompted the College of Nuclear Physicians of South Africa, in collaboration with university hospitals, to develop a list of recommendations on the appropriate use of fluorine-18-fluorodeoxyglucose $\left({ }^{18} \mathrm{~F}-\mathrm{FDG}\right)$ and non- ${ }^{18} \mathrm{~F}$-FDG PET/CT in oncology, cardiology, neurology and infection/inflammation. It is expected that other clinical situations will be added to these recommendations, provided that they are based upon solid clinical evidence. These recommendations are intended to offer advice regarding contemporary applications of PET/CT, as well as indicating novel developments and potential future indications. The CNP believes that these recommendations will serve an important and relevant role in advising referring physicians on the appropriate use of ${ }^{18} \mathrm{~F}-\mathrm{FDG}$ and non ${ }^{18} \mathrm{~F}$-FDG PET/CT. More promising clinical applications will be possible in the future, as newer PET tracers become more readily available.

S Afr Med J 2015;105(11):894-896. DOI:10.7196/SAMJ.2015.v105i11.10180
\end{abstract}

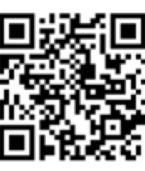

A patient-tailored treatment approach demands precise determination of initial disease extent combined with early, accurate assessment of response to treatment. Positron emission tomography/computed tomography (PET/CT) is currently the most widely used molecular imaging technology and is central to the advancement of patient care and biological research. ${ }^{[1,2]}$

\section{PET/CT whole-body imaging}

PET is a non-invasive tool that provides tomographic images and quantitative parameters of perfusion, cell viability, and proliferation and/or metabolic activity of tissues. These images result from the use of various biological compounds (such as sugars, amino acids, metabolic precursors and hormones) labelled with positronemitting radionuclides (PET radiopharmaceuticals). ${ }^{[1]}$ Fusion of the functional information with the morphological detail provided by $\mathrm{CT}$ as PET/CT can provide clinicians with a sensitive and accurate one-step whole-body diagnostic and prognostic tool, which directs and changes patient management. ${ }^{[1,3]}$

Several studies have demonstrated the superiority of combined $\mathrm{PET} / \mathrm{CT}$ over either modality alone, and for many indications this is generally accepted as the gold standard for imaging in oncology. ${ }^{[4]}$ The value of PET/CT imaging has been best demonstrated in the setting of oncology with the use of fluorine-18-fluorodeoxyglucose ( $\left.{ }^{18} \mathrm{~F}-\mathrm{FDG}\right)$. FDG is an analogue of glucose and is taken up by cells via the first stages of the normal glucose pathway and trapped inside cells with high glucose transporter expression and/or glycolytic activity. Tumour uptake therefore correlates with tumour growth and viability, providing metabolic quantification and frequently useful information for tumour characterisation, patient prognosis and monitoring of therapeutic response. ${ }^{[1]}$

\section{Impact on the management of oncology patients}

Current data suggest that in as many as one-third to one-half of cancer cases, physicians without access to PET are at an increased risk of selecting the wrong management/treatment strategy for their patients. Three large-scale national studies published by the National Oncologic PET Registry in the USA have shown that PET imaging changes the intended patient management strategy in $36.5 \%, 38 \%$ and $49 \%$ of cases, respectively. ${ }^{[5-7]}$ Results were consistent across all cancer types. ${ }^{[6]} \mathrm{A}$ recent study by Worsley et al.$^{[8]}$ found that the information derived from PET 
imaging resulted in a change in intended treatment plans in $50 \%$ of cases. $^{[8]}$ In up to $90 \%$ of cases, referring physicians indicated that PET/ CT enabled them to avoid additional imaging tests or procedures. ${ }^{[7]}$ It is largely on this basis that PET can significantly reduce the number of tests performed, with substantial healthcare savings if it is done at the beginning of the diagnostic pathway rather than as a last resort. PET imaging has enabled physicians to avoid costly biopsy and surgery in as many as $70 \%$ of cases. ${ }^{[5]}$ This can also result in significant cost savings and prevent patients from undergoing high-risk surgical procedures.

\section{The South African context}

South Africa (SA) is recognised as a world leader in the provision of medical isotopes and has centres of global excellence in PET for oncology, infection, neurology and personalised medicine. ${ }^{[9]}$ $\mathrm{SA}$ is among a minority of countries that can provide both ${ }^{18} \mathrm{~F}-$
FDG and non- ${ }^{18} \mathrm{~F}$-FDG tracers, including ${ }^{18} \mathrm{~F}-\mathrm{NAF},{ }^{18} \mathrm{~F}$-choline, ${ }^{68} \mathrm{Ga}$-DOTATATE/DOTATOC, and ${ }^{68} \mathrm{Ga}$-PSMA for clinical use. We have already observed the significant clinical impact of ${ }^{18} \mathrm{~F}-\mathrm{FDG}$ PET/ $\mathrm{CT}$ in the management of cancer patients, similar to that published by Hillner et al. ${ }^{[6,7]}$ and Worsely et al. ${ }^{[8]}$

Evidence is also rapidly accumulating for multiple non-oncological indications in the fields of cardiology, ${ }^{[10]}$ neurology ${ }^{[11]}$ and infection imaging. ${ }^{[12]}$ This growth is expected to continue with existing tracers, and with the numerous possibilities created by new tracers. ${ }^{[13]}$

The proven clinical effectiveness and growing importance of PET/ CT have prompted the College of Nuclear Physicians (CNP) of the Colleges of Medicine of South Africa, in collaboration with university hospitals, to develop a list of recommendations on the appropriate use of ${ }^{18} \mathrm{~F}-\mathrm{FDG}$ and non- ${ }^{18} \mathrm{~F}-\mathrm{FDG}$ PET/CT in oncology, cardiology, neurology and infection/inflammation. This has resulted in a well-

Table 1. Summary of the appropriate indications for PET/CT

\begin{tabular}{|c|c|c|c|c|c|c|c|}
\hline Disease & Screening & Diagnosis & Staging & $\begin{array}{l}\text { Restaging/response } \\
\text { post therapy }\end{array}$ & $\begin{array}{l}\text { Suspected } \\
\text { recurrence }\end{array}$ & Surveillance & $\begin{array}{l}\text { Radiotherapy } \\
\text { planning }\end{array}$ \\
\hline CNS tumours & & Rs & & $\mathrm{C}$ & Rs & & \\
\hline Head \& neck & $\mathrm{C}$ & Rs & Rs & $\mathrm{R}$ & $\mathrm{R}$ & & $\mathrm{R}$ \\
\hline Thyroid & & & Rs & Rs & Rs & & \\
\hline Thymus & & $\mathrm{C}$ & $\mathrm{C}$ & $\mathrm{C}$ & $\mathrm{C}$ & & \\
\hline Breast & & $\mathrm{C}$ & Rs & Rs & $\mathrm{R}$ & & \\
\hline Lymphoma & & $\mathrm{C}$ & $\mathrm{R}$ & Rs & Rs & & $\mathrm{C}$ \\
\hline Langerhans cell histiocytosis & & & $\mathrm{C}$ & $\mathrm{C}$ & $\mathrm{C}$ & $\mathrm{C}$ & \\
\hline Multiple myeloma & & $\mathrm{C}$ & Rs & $\mathrm{C}$ & Rs & $\mathrm{C}$ & \\
\hline Carcinoma unknown primary & & Rs & Rs & & & & \\
\hline Paraneoplastic syndrome & Rs & & & & & & \\
\hline Melanoma & & & Rs & Rs & Rs & & \\
\hline Lung cancers & & Rs & Rs & $\mathrm{C}$ & $\mathrm{C}$ & & $\mathrm{C}$ \\
\hline Pleural/mesothelioma & & $\mathrm{C}$ & Rs & & $\mathrm{C}$ & & $\mathrm{C}$ \\
\hline Oesophagus & & & Rs & Rs & Rs & $\mathrm{C}$ & $\mathrm{C}$ \\
\hline Gastric \& pancreas & & & $\mathrm{C}$ & $\mathrm{C}$ & $\mathrm{C}$ & $\mathrm{C}$ & $\mathrm{C}$ \\
\hline Colorectal and anal & & & Rs & Rs & $\mathrm{R}$ & $\mathrm{C}$ & $\mathrm{C}$ \\
\hline Hepatobiliary & & & $\mathrm{C}$ & & & & \\
\hline Sarcoma & & $\mathrm{C}$ & Rs & $\mathrm{C}$ & $\mathrm{C}$ & $\mathrm{C}$ & $\mathrm{C}$ \\
\hline GIST & & & Rs & Rs & $\mathrm{C}$ & & \\
\hline Genitourinary tract cancers & & & $\mathrm{C}$ & $\mathrm{C}$ & & & \\
\hline Male reproductive system & & & $\mathrm{C}$ & Rs & $\mathrm{C}$ & & $\mathrm{C}$ \\
\hline Female reproductive system & & & Rs & Rs & Rs & & $\mathrm{C}$ \\
\hline \multicolumn{8}{|l|}{ Non-FDG PET } \\
\hline $\begin{array}{l}\text { Neuroendocrine tumours } \\
\left({ }^{68} \mathrm{Ga} \text {-DOTATATE }\right)\end{array}$ & & $\mathrm{C}$ & Rs & $\mathrm{C}$ & $\mathrm{C}$ & $\mathrm{C}$ & $\mathrm{C}$ \\
\hline Neuroendocrine tumours $\left({ }^{18} \mathrm{~F}-\mathrm{FDG}\right)$ & & & Rs & $\mathrm{C}$ & & & \\
\hline Sodium fluoride $\left({ }^{18} \mathrm{~F}-\mathrm{NaF}\right)$ & & $\mathrm{C}$ & & & & & \\
\hline $\begin{array}{l}\text { Prostate cancer }\left({ }^{18} \mathrm{~F} \text {-choline, }\right. \\
\left.{ }^{68} \mathrm{Ga} \text {-PSMA }\right)\end{array}$ & & $\mathrm{C}$ & $\mathrm{C}$ & $\mathrm{C}$ & Rs & & $\mathrm{C}$ \\
\hline Paediatric oncology & & $\mathrm{C}$ & Rs & Rs & $\mathrm{C}$ & & $\mathrm{C}$ \\
\hline Neurology & & Rs & & & & & \\
\hline Cardiology & & Rs & & & & & \\
\hline
\end{tabular}


established list of recommendations on the use of both ${ }^{18} \mathrm{~F}-\mathrm{FDG}$ and non ${ }^{18}$ F-FDG PET/CT in these fields.

The CNP has focused on defining those clinical conditions particular to the SA context, and where PET/CT could potentially result in the highest patient impact, with the intention of optimising the cost-effectiveness of its utilisation. ${ }^{[14,15]}$ In addition, emphasis has been placed on the need for clinical benefit to be demonstrated together with accuracy. This principle has also been expressed by Schuenemann et al.: ${ }^{[16]}$ 'If a test fails to improve patient-important outcomes, there is no reason to use it, whatever its accuracy. This idea is not new, and remains one of several steps in establishing diagnostic procedures. ${ }^{[17,18]}$

\section{Explanation of recommendations}

Our recommendations on the appropriate use of PET/CT are based on the search for the best clinical evidence in the medical literature. In order to achieve consistency and avoid ambiguity, recommendations on the use of PET/CT for individual indications have been categorised as:

1. Recommended: PET/CT is generally appropriate for this indication. There is a strong base of evidence supporting its use and/or it is currently recommended by international clinical guidelines.

2. Recommended in select cases: PET/CT is appropriate for this indication in cases meeting clearly defined criteria. In this specific context there is a strong base of evidence supporting its use and/or it is currently recommended by international clinical guidelines.

3. May be considered: PET/CT is generally not appropriate for this indication; however, it may be appropriate in individual cases with a strong motivation. Typically there may be some evidence or a strong rationale to support the use of PET/CT in special circumstances.

4. Not recommended: PET/CT is generally not appropriate for this indication. Typically there is a low level of evidence and/or weak rationale for its use, and it is not endorsed by international clinical guidelines.

The recommendations and practical guidelines developed by the CNP for the use of ${ }^{18} \mathrm{~F}-\mathrm{FDG}$ and non- ${ }^{18} \mathrm{~F}$-FDG PET/CT are summarised in Table 1, and the full details will be available in part 2 of the January 2016 issue of $S A M J .^{[19]}$

\section{Conclusion}

It is important to note that it is expected that other clinical situations will be added to these recommendations, provided that they are based upon solid clinical evidence.

Although the availability of metabolic functional imaging has greatly enhanced our understanding of a range of pathological processes, and provided new opportunities for incorporation of this information into patient management protocols, growth of PET globally and in SA is constrained by cost, infrastructure and education. ${ }^{[20]}$ The World Heath Organization recommends that countries adopt a PET scanner ratio of two scanners per million people. $^{[21]}$ This suggests that SA would require approximately 100 PET scanners - ten times the current number.

Attaining this goal would require a financial commitment commensurate with policy priorities that include resources for equipment, radiotracer production and distribution, infrastructure, and the education of physicians and healthcare consumers. Currently this is not achievable.
The cost of PET/CT in SA ranges from ZAR12 000 in the public sector to ZAR20 000 in the private sector. With the limited resources we have, it is therefore important to avoid the inappropriate use of PET/CT. The limited knowledge of PET on the part of many referring physicians is a growing concern, and is a commonly cited factor contributing to the underutilisation of existing PET scanners in some departments. SA doctors tend to use PET imaging at the end of the diagnostic pathway, which may prevent cost-effective care. Similarly, the inappropriate use of PET/ $\mathrm{CT}$ is not cost-effective. There is therefore a need for education and training of caregivers, doctors, patients and healthcare officials. The CNP recommendations ${ }^{[19]}$ are intended to offer advice regarding contemporary applications of PET/CT, as well as indicating novel developments and potential future indications. The CNP believes that these recommendations will serve an important and relevant role in advising referring physicians on the appropriate use of ${ }^{18} \mathrm{~F}-\mathrm{FDG}$ and non- ${ }^{18} \mathrm{~F}-\mathrm{FDG}$ PET/CT, which can be a powerful tool in patient management in oncology, cardiology, neurology and infection/inflammation.

More promising clinical applications will be possible in the future, as newer PET tracers become more readily available.

1. Boellaard R, O'Doherty MJ, Weber WA, et al. FDG PET and PET/CT: EANM procedure guidelines for tumour PET imaging: version 1.0. Eur J Nucl Med Molec Imaging 2010;37(1):181-200. [http://dx.doi. $\mathrm{rg} / 10.1007 /$ s00259-009-1297-4]

2. Royal College of Physicians and Royal College of Radiologists. Evidence-based Indications for the Use of PET-CT in the UK. London: RCP, RCR, 2013. www.rcr.ac.uk/docs/radiology/pdf/2013_PETCT_ RCP_RCR.pdf (accessed 6 January 2015).

3. PET Professional Resources and Outreach Source. NCCN Practice Guidelines Tabular Summary PET and PET/CT. 2011. http://www.snm.org/docs/PET_PROS/NCCNPracticeGuidelinesI.pdf (accessed 22 November 2011).

Gao G, Gong B, Shen W. Meta-analysis of the additional value of integrated 18F-FDG PET-CT for tumor distant metastasis staging: Comparison with 18F-FDG PET alone and CT alone. Surg Oncol 2013;22(3):195-200. [http://dx.doi.org/10.1016/j.suronc.2013.06.004]

5. Hillner BE, Siegel BA, Liu D, et al. Impact of positron emission tomography/computed tomography and positron emission tomography (PET) alone on expected management of patients with cancer: Initial results from the national oncologic PET registry. J Nucl Med 2008;49(13):1928-1935. [http:// Initial results from the national oncologc
dx.doi.org $/ 10.2967 /$ inumed.108.056713]

6. Hillner BE, Siegel BA, Shields AF, et al. Relationship between cancer type and impact of PET and 6. Hillner BE, Siegel BA, Shields AF, et al. Relationship between cancer type and impact of PET and
PET/CT on intended management: Findings of the national oncologic PET registry. J Clin Oncol 2008;26(13):2156-2161. [http://dx.doi.org/10.2967/jnumed.108.056713]

7. Hillner BE, Siegel BA, Shields AF, et al. The impact of positron emission tomography (PET) on expected management during cancer treatment. Cancer 2009;115(2):410-418. [http://dx.doi. org/10.1002/cncr.24000

8. Worsley DF, Wilson DC, Powe JE, et al. Impact of F-18 fluorodeoxyglucose positron emission tomographycomputed tomography on oncologic patient management: First 2 years' experience at a single Canadian cancer centre. Can Assoc Radiol J 2010;61(1):13-18. [http://dx.doi.org/10.1016/j.carj.2009.07.005]

9. Sathekge M, Maes A, van der Wiele C. FDG-PET imaging in HIV infection and tuberculosis. Semin Nucl Med 2013;43(5):349-366. [http://dx.doi.org/10.1053/.semnuclmed.2013.04.008]

10. Flotats A, Knuuti J, Gutberlet M, et al. Hybrid cardiac imaging: SPECT/CT and PET/CT. A joint position statement by the European Association of Nuclear Medicine (EANM), the European Society position statement by the European Association of Nuclear Medicine (EANM), the European Society
of Cardiac Radiology (ESCR) and the European Council of Nuclear Cardiology (ECNC). Eur J Nucl of Cardiac Radiology (ESCR) and the European Council of Nuclear Cardiology (ECNC).
Med Mol Imaging 2011;38(1):201-212. [http://dx.doi.org/10.1007/s00259-010-1586-y]

11. Tripathi M, Damle N, Kushwaha S, et al. Differential diagnosis of neurodegenerative dementias using metabolic phenotypes on F-18 FDG PET/CT. Neuroradiology 2014;27(1):13-21. [http://dx.doi. org/10.15274/NRJ-2014-10002

12. Israel O, Keidar Z. PET/CT imaging in infectious conditions. Ann N Y Acad Sci 2011;1228(1):150-166. [http://dx.doi.org/10.1111/j.1749-6632.2011.06026.x]

13. Núñez MR, Pozo MA. Non-FDG PET in oncology. Clinical and Translational Oncology 2011;13(11):780-786. [http://dx.doi.org/10.1007/s12094-011-0733-7]

14. Sathekge M, Maes A, Kgomo M, Pottel H, Stolz A, van de Wiele C. FDG uptake in lymph-nodes of HIV+ and tuberculosis patients: Implications for cancer staging. Q J Nucl Med Mol Imaging 2010;54(6):698-703

15. Simonds HM, Warwick J, Ellmann A. Introduction of PET/CT scanning impacts treatment decisions in the management of cervix carcinoma patients in a public hospital. World J Nucl Med 2010;9:S152.

6. Schuenemann HJ, Oxman AD, Brozek J, et al. GRADE: Assessing the quality of evidence for diagnostic recommendation,

17. Fryback DG, Thornbury J. The efficacy of diagnostic imaging. Med Decis Making 1991;11(2):88-94. [http://dx.doi.org/10.1177/0272989X9101100203].

18. Köbberling J, Trampisch H, Windeler J. Memorandum for the evaluation of diagnostic measures. J Clin Chem Clin Biochem 1990;28(12):873-879.

19. Vorster M, Doruyter A, Brink A, et al. Appropriate indications for positron electron tomography/ computed tomography, 2015. S Afr Med J 2016;106(1)(in press). [http://dx.doi.org/10.7196/SAMJ.2015. v105i11.10181]

20. Sathekge MM, Warwick J, Vangu MDT, Ellmann A, Mann M. A case for the provision of positron emission tomography (PET) in South African public hospitals. S Afr Med J 2006;96(7):598. 600-601.

21. MEDEC. Positron Emission Tomography (PET) Task Force Report for Ontario. Toronto: MEDEC, 2010. 